\title{
Biokonversi Limbah Tongkol Jagung Menjadi Bioetanol Sebagai Bahan Bakar Alternatif Terbarukan
}

\author{
Hendri lyabu ${ }^{1 *}$, Ishak Isa ${ }^{2}$ \\ ${ }^{1,2}$ Program Studi Kimia, Universitas Negeri Gorontalo, Jl. Jend. Sudirman No.6, Kota Gorontalo,96128
}

\begin{abstract}
ABSTRAK
Penelitian ini bertujuan untuk mengkonversi lignoselulosa dari jagung tongkol limbah menjadi bioetanol sebagai bahan bakar alternatif terbarukan. Proses pembuatan etanol dari kotoran jagung sampah dapat melalui tiga tahapan yang penting, menghidrolisis lignocellulose menjadi gula, fermentasi gula ke dalam pemurnian etanol andethanol. Proses menghidrolisis kimia menggunakan asam sulfat encer. Fermentasi gula ke etanol menggunakan Saccharomyces Cerevisiae, sedangkan pemurnian alkohol yang dihasilkan melalui proses distilasi. Hasil penelitian menunjukkan bahwa alkohol (etanol) konsentrasi yang diperoleh masih di bawah standar yang diinginkan sebagai alternatif energi untuk bahan bakar fosil.
\end{abstract}

Kata kunci: tongkol jagung; bioetanol; biokonversi; energi terbarukan

\begin{abstract}
The aims of this research is to convert Lignocellulose from corn cobs waste into bioethanol as a renewable alternative fuel. The process of making ethanol from corn cobs waste can be through three important stages, hydrolyze lignocellulose to sugars, fermentation of sugars to ethanol andethanol purification. The hydrolyze process of chemically using dilute sulfuric acid. Fermentation of sugars to ethanol using Saccharomyces cerevisiae, while the purification of alcohol produced through the distillation process. The results showed that the alcohol (ethanol) obtained concentration is still below the desired standards as an energy alternative to fossil fuel.
\end{abstract}

Keywords: corn cob; bioethanol; bioconversion; renewable energy

Received: 31-07-2019, Accepted: 12-09-2019, Online: 30-09-2019

\section{PENDAHULUAN}

Indonesia merupakan negara yang kaya akan sumberdaya alam yang sangat berlimbah, baik sumberdaya alam yang dapat diperbaharui maupun tidak dapat diperbaharui. Minyak bumi dan batu bara merupakan contoh bahan bakar yang tidak dapat diperbaharuhi yang ketersediaanya di alam semakin menipis. Dengan menipisnya bahan bakar ini maka sudah dapat dipastikan akan berdampak pada krisis global energi.

Jagung merupakan salah satu komoditi unggulan provinsi Gorontalo, dimana produksi jagung gorontalo dari tahun ketahun mengalami peningkatan. Disamping untuk memenuhi kebutuhan hidup masyarakat gorontalo, jagung juga telah dieksport ke luar negeri seperti Malaysia dan Singapura untuk bahan baku berbagai produk seperti tepung jagung (maizena), pati jagung, minyak jagung, dan pakan ternak. Dari setiap 
panen jagung diperkirakan jagung (rendemen) yang dihasilkan sekitar 65\%, sementara $35 \%$ dalam bentuk limbah berupa batang, daun, kulit, dan tongkol jagung.

Saat ini telah diketahui bahwa limbah tongkol jagung dapat digunakan sebagai bahan baku pembuatan bioetanol. Tongkol jagung merupakan limbah buangan pada industri jagung pipil yang ternyata mengandung selulosa sebesar $44.9 \%$ (Richana dkk, 2004), dan kurang lebih 30\% bagian jagung merupakan tongkol jagung. Kenyataan tersebut membuat limbah tongkol jagung dari industri jagung pipil mempunyai potensi untuk dimanfaatkan sebagai bahan baku pembuatan bioetanol karena kandungan selulosa yang cukup tinggi.

Dengan menggali kemajuan ilmu pengetahuan dan teknologi, produksi bioetanol dari limbah tongkol jagung dapat dilakukan dengan memanfaatkan teknologi fermentasi. Proses pembuatan bioetanol dari tongkol jagung dapat dilakukan dengan beberapa cara. Namun, secara umum ada lima tahap proses utama. Tahapan tersebut adalah delignifikasi tongkol jagung, isolasi selulosa, hidrolisis, fermentasi, dan distilasi etanol.

Delignifikasi bertujuan untuk memudahkan pelepasan hemiselulosa dan mengurangi kandungan lignin pada tongkol jagung yang dapat menghambat fermentasi selulosa menjadi gula-gula sederhana. Delignifikasi dilakukan dengan beberapa tahapan, yaitu pengecilan ukuran, perendaman dalam $\mathrm{NaOCl} 1 \%(b / v)$, pembilasan, penyaringan, dan pengeringan untuk menurunkan kadar air tongkol jagung (Anggraini, 2003). Pembilasan dan penyaringan dengan air dilakukan sampai air bilasan menjadi netral.

Isolasi selulosa dilakukan untuk mengekstrak hemiselulosa dari fraksi selulosa pada tongkol jagung. Menurut Hespell (1998), ekstraksi hemiselulosa paling baik dilakukan dengan menggunakan pelarut $\mathrm{NaOH}$. Isolasi selulosa dilakukan dengan perendaman tongkol jagung yang telah didelignifikasi dalam larutan $\mathrm{NaOH} 15 \%$ selama 24 jam pada suhu $28^{\circ} \mathrm{C}$. Setelah 24 jam, dilakukan penyaringan hingga didapatkan fraksi padatan berupa selulosa. Padatan tersebut dibilas berulang-ulang dengan air sampai $\mathrm{pH}$ menjadi netral. Kemudian dikeringkan dengan oven suhu $50^{\circ} \mathrm{C}$ selama 2 hari.

Dengan memperhatikan prospek bioetanol yang cukup cerah yang benilai ekonomi yang cukup tinggi, maka sangatlah perlu dilakukan penelitian tentang pemanfaatan limbah tongkol jagung menjadi bioetanol sebagai energi alternatif terbarukan yang ramah lingkungan.

\section{METODE PENELITIAN}

\section{Alat dan Bahan}

Alat yang digunakan dalam penelitian ini adalah Seperangkat alat destilasi, neraca analitik, tabung reaksi, rak tabung, gilingan jagung, ayakan, labu takar, gelas ukur, gelas kimia, alkohol meter, indikator universal, oven, autoclave, penangas air, kapas, tisue, labu erlenmeyer, aluminium foil, batang pengaduk, botol reagen, pipet tetes, pipet mikro, pembakar bunsen, jarum ose, spektrofotometer, colony counter, seperangkat alat titrasi, sendok, kertas saring, inkubator, cawan petri, shaker inkubator(inkubator goyang), Erlenmeyer, Laminar Air Flow.

Bahan-bahan yang digunakan dalam penelitian ini yaitu tongkol jagung, $\mathrm{H}_{2} \mathrm{SO}_{4}$ (0,1 M, 0,3 M, dan 0,5 M), Alkohol Standar, Ammonium Sulfat (ZA) 0,9 gr (sebagai nutrisi), Urea 0,48 gram (sebagai nutrisi), Aquadest, Saccharomyces cerevisiae, PDA (Potato Dextrose Agar), PDB (Potato Dextrose Broth), $\mathrm{NaOH}$, reagen luff schoorl, $\mathrm{H}_{2} \mathrm{SO}_{4} 25 \%$, indikator amilum, $\mathrm{KI} 10 \%, \mathrm{Na}_{2} \mathrm{~S}_{2} \mathrm{O}_{3} 0,1 \mathrm{~N}$. 


\section{Prosedur Penelitian}

\section{Tahap Pra Penelitian}

Perlakuan fisik terhadap tongkol jagung meliputi pencucian, pengeringan, penggilingan dan pengayaan. Pencucian dilakukan untuk menghilangkan bahan-bahan yang terikut dalam tongkol seperti tanah dan kotoran lainnya. Pengeringan dilakukan dibawah sinar matahari hingga tongkol jagung menjadi kering betul. Tujuan dari pengeringan yaitu untuk memudahkan dalam proses penggilingan serat tongkol jagung, karena pada keadaan lembab tongkol jagung sukar untuk dihancurkan. Tahap penghancuran bertujuan untuk memperkecil ukuran tongkol jagung. Semakin kecil ukuran tongkol jagung maka akan semakin mudah untuk digiling/dihancurkan. Alat yang digunakan adalah gilingan jagung, tongkol yang sudah dihancurkan kemudian diayak dengan ukuran \pm 40 mesh.

\section{Tahap Penelitian}

\section{Pembiakan khamir dengan Media Cair}

Pada tahap pembiakan mikroba, langkah-langkah yang dilakukan yaitu mengambil $100 \mathrm{~mL}$ dimasukkan ke dalam gelas kimia. Kemudian ditambahkan PDB (Potato Dextrose Broth) sebagai media pertumbuhan mikroba sebanyak 2,4 g. Dipanaskan sambil diaduk setelah mendidih diangkat. Dimasukkan kedalam labu erlenmeyer, ditutup dengan kapas dan alumminium foil agar tidak ada bakteri lain yang masuk kedalam PDB. Setelah itu disterilisasi didalam autoclave hingga suhu $121{ }^{\circ} \mathrm{C}$. Kemudian diangkat dan disimpan didalam lemari Laminar Air Flow hingga PDB (Potato Dextrose Broth) dingin. Setelah itu khamir murni dimasukkan kedalam erlenmeyer yang berisi PDB (Potato Dextrose Broth). Didiamkan di shaker inkubator selama 2 hari agar pertumbuhan bakteri merata (tidak mengendap).

\section{Pembiakkan Khamir dengan Media Agar}

Langkah-langkah yang dilakukan yaitu memasukkan $30 \mathrm{~mL}$ aquades kedalam gelas kimia. Ditambahkan PDA (Potato Dextrose Agar) sebanyak 1,08 g. Dipanaskan sambil diaduk setelah mendidih diangkat. Kemudian disiapkan 5 buah tabung reaksi. Kemudian memasukkan PDA (Potato Dextrose Agar) yang telah mendidih ke dalam masing-masing tabung reaksi sebanyak $6 \mathrm{~mL}$ untuk setiap tabung. Setelah itu ditutup dengan kapas dan alumminium foil. Tabung dimiringkan. Setelah PDA (Potato Dextrose Agar) padat, gores dengan menggunakan jarum ose yang telah di celupkan kedalam PDB (Potato Dextrose Broth) yang telah dibiakan Saccharomyces cerevisiae selama 2 hari. Saccharomyces cerevisiae diinkubasi selama 7 hari.

\section{Tahap Hidrolisis}

Langkah awal yang dilakukan menimbang tepung tongkol jagung sebanyak $100 \mathrm{~g}$. Kemudian dimasukan kedalam erlenmeyer $1.000 \mathrm{~mL}$. Ditambahkan $1.000 \mathrm{~mL}$ larutan $\mathrm{H}_{2} \mathrm{SO}_{4}$ dengan variasi kosentrasi 0,$1 ; 0,3 \mathrm{M} ; 0,5 \mathrm{M}$. Setelah itu dihidrolisis pada suhu $100^{\circ} \mathrm{C}$ selama 2 jam. Kemudian disaring untuk memisahkan filtrat dan residu.

\section{Uji Kadar Glukosa}

Langkah-langkah yang dilakukan yaitu mengambil $3 \mathrm{~mL}$ filtrat tepung tongkol jagung yang telah dihidrolisis. Kemudian diencerkan dengan $50 \mathrm{~mL}$ Aquades. Diambil $10 \mathrm{~mL}$ larutan. Ditambahkan $25 \mathrm{~mL}$ reagen luff schoorl, dimasukan batu didih. Setelah itu dipanaskan selama 2 menit, kemudian diangkat dan didinginkan. Kemudian ditambhakan $15 \mathrm{~mL} \mathrm{KI} \mathrm{30 \%} \mathrm{dan} 25 \mathrm{~mL} \mathrm{H}_{2} \mathrm{SO}_{4} 25 \%$. Setelah itu dititrasi dengan larutan $\mathrm{Na}_{2} \mathrm{~S}_{2} \mathrm{O}_{3} 0,1 \mathrm{~N}$ hingga terjadi perubahan warna menjadi cokelat muda. Ditambahkan 1 
$\mathrm{mL}$ indikator amilum. Kemudian dititrasi kembali hingga larutan menjadi jernih. Dilakukan perlakuan yang sama pada blanko.

\section{Tahap Fermentasi}

Pada tahap ini, langkah-langkah yang dilakukan yaitu menambahkan 0,9 g Ammonium sulfat dan $0,48 \mathrm{~g}$ Urea sebagai nutrisi pada filtrat hasil hidrolisis yang memiliki kadar glukosa terbanyak dan mengatur pHnya 4-4,5. Kemudian menyiapkan 4 buah erlenmeyer. Pada masing-masing erlenmeyer masukkan $100 \mathrm{~mL}$ sampel. Setelah itu dimasukkan kedalam autoclave untuk disterilisi hingga suhu mencapai $121{ }^{\circ} \mathrm{C}$. Kemudian diangkat dan didinginkan didalam lemari Laminar Air Flow selama 24 jam. Kemudian ditambahkan 2 ose Saccharomyces cerevisiae pada masing-masing tabung. Setelah itu sampel dimasukan kedalam inkubator selama variasi waktu yang telah ditentukan (3,5,7,dan 9 hari).

\section{Tahap pengenceran sampel untuk perhitungan jumlah mikroba/koloni}

Pada tahap pengenceran sampel langkah yang dilakukan yaitu menyiapkan PDA, 8 buah tabung reaksi dan 8 buah cawan petri diberi label $10^{-1}-10^{-8}$ pada masingmasing tabung dan cawan. Kemudian dimasukkan $9 \mathrm{~mL}$ aquades kedalam tabung reaksi. Kemudian aquades tabung dan $120 \mathrm{~mL}$ PDA disterilisasi didalam autoclave. Setelah itu diangkat dan didinginkan hingga suhu maksimal $40^{\circ} \mathrm{C}$. Diambil $1 \mathrm{~mL}$ sampel hasil fermentasi. Kemudian dimasukkan kedalam tabung reaksi pertama $\left(10^{-1}\right)$ yang berisi aquades dan divortex hingga larutan homogen. Setelah itu diambil $1 \mathrm{~mL}$ larutan pada tabung pertama dan dimasukkan pada tabung kedua $\left(10^{-2}\right)$ menggunakan pipet mikro kemudian divortex. Dilakukan perlakuan yang sama untuk tabung 3-8. Kemudian pada masing-masing tabung di ambil $0,5 \mathrm{~mL}$ larutan dan dimasukkan kedalam masingmasing cawan yang telah diberi label. Ditambahkan $15 \mathrm{~mL}$ larutan PDA kemudian didiamkan hingga PDA memadat. Setelah itu dimasukkan kedalam inkubator selama \pm 48 jam. Kemudian dihitung jumlah koloni/khamir yang tumbuh pada masing-masing cawan dengan menggunakan colony counter.

\section{Tahap Destilasi}

Pada tahap ini filtrat hasil fermentasi dengan variasi waktu tertentu dimasukkan kedalam labu leher tiga. Kemudian didestilasi pada suhu $78^{\circ} \mathrm{C}-80^{\circ} \mathrm{C}$ (suhu alkohol).

\section{Pengukuran Kadar Bioetanol menggunakan Alkoholmeter}

Untuk mengukur kadar bioetanol langkah awal yang dilakukan adalah mengukur kadar etanol standar. Kemudian mengukur bioetanol hasil destilasi dengan cara memasukkan destilat tersebut kedalam gelas ukur minimal $40 \mathrm{~mL}$. Kemudian dimasukkan alkoholmeter kedalam gelas kimia. Didiamkan selama 5-10 menit. Dilihat skala yang terbaca pada alkoholmeter.

\section{HASIL DAN PEMBAHASAN}

\section{Tahap Pra Penelitian (Preparasi Sampel)}

Tongkol jagung yang digunakan dalam penelitian ini sebanyak 98 buah. Tepung tongkol jagung yang dihasilkan setelah pengolahan sebanyak 889,19 gr. Hasil pengolahan tongkol jagung menjadi tepung tongkol jagung dapat dilihat pada gambar 1 . 

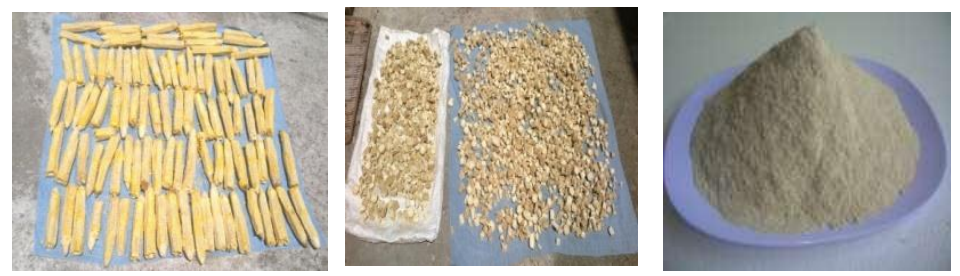

Gambar 1. Tahap Pengolahan Tongkol jagung menjadi Tepung Tongkol jagung

\section{Pengaruh Variasi Kosentrasi $\mathrm{H}_{2} \mathrm{SO}_{4}$ Pada Proses Hidrolisis terhadap Kadar Glukosa}

Pada proses hidrolisis digunakan asam sulfat encer pada konsentrasi $0,1 \mathrm{M}, 0,3$ $\mathrm{M}$, dan 0,5 M. Penggunaan asam sulfat dengan kosentrasi yang berbeda bertujuan untuk mencari konsentrasi yang tepat untuk menghasilkan gula yang tinggi dari substrat tongkol jagung. Waktu yang digunakan pada hidrolisis selama 120 menit dan dipertahankan pada suhu $100^{\circ} \mathrm{C}$. Menurut Idral dkk (2012) waktu hidrolisis yang baik adalah 120 menit, karena jika waktu hidrolisis terlalu lama maka glukosa akan terdegradasi dan bereaksi lebih lanjut membentuk asam format, sehingga menyebabkan kadar glukosa menurun. Menurut Feneiet,. at al dalam Anieto (2010), bahwa waktu hidrolisis selama 120 menit merupakan waktu yang optimum dalam menghasilkan glukosa terbanyak. Pada dasarnya prinsip hidrolisis adalah memutuskan rantai polimer bahan menjadi unit-unit monomer yang lebih sederhana dengan bantuan katalis.

Pengukuran kadar glukosa dilakukan dengan menggunakan metode Luff Schoorl. Tujuan pengukuran kadar glukosa yaitu untuk mengetahui persentase glukosa pada masing-masing sampel. Pengukuran kadar glukosa dengan metode Luff Schoorl ini dapat dihitung dengan rumus pada halaman 11. Hasil perhitungan dapat dilihat pada lampiran II (halaman 38) menunjukkan bahwa kadar glukosa paling banyak terdapat pada hidrolisis dengan menggunakan larutan 0,3 $\mathrm{M}$ sehingga hasil hidrolisis dengan menggunakan larutan $\mathrm{H}_{2} \mathrm{SO}_{4}$ 0,3 $\mathrm{M}$ inilah yang paling bagus digunakan untuk proses fermentasi. Semakin banyak kadar glukosa yang terkandung dalam sampel maka semakin banyak pula bioetanol yang akan dihasilkan pada saat fermentasi.

\section{Pengaruh Waktu Fermentasi Terhadap Kadar Bioetanol dan Jumlah Saccharomyces cerevisiae}

Bioetanol yang dihasilkan melalui proses fermentasi masih bercampur secara homogen dengan air. Oleh sebab itu, dilakukan proses destilasi. Proses destilasi yang didasarkan perbedaan titik didih air $\left(100^{\circ} \mathrm{C}\right)$ dan titik didih bioetanol $\left(78^{\circ} \mathrm{C}\right)$, sehingga yang akan menguap terlebih dahulu adalah bioetanol. Dengan menjaga suhu $78^{\circ} \mathrm{C}$ pada saat destilasi maka hanya komponen bioetanol saja yang akan menguap. Sehingga destilat yang dihasilkan adalah bioetanol. Setelah didestilasi, destilat diukur dengan menggunakan alkoholmeter. Sebelum dilakukan pengukuran pada sampel sebaiknya alkoholmeter dikalibrasi terlebih dahulu menggunakan alkohol absolut/alkohol standar. Tujuan kalibrasi ini yaitu untuk memastikan alat tersebut layak atau tidaknya untuk digunakan. Selain itu, persen kadar alkohol standar yang terbaca oleh alkholmeter nantinya digunakan dalam perhitungan faktor koreksi. Masing-masing kadar bioetanol pada sampel yang terukur dengan alkoholmeter yaitu pada fermentasi hari ke $3(2 \%)$, hari ke 5 dan ke $7(5 \%)$, dan pada hari ke $9(3 \%)$. Kadar bioetanol yang terukur dengan menggunakan alcoholmeter, hasil perhitungan kadar bioetanol dapat dilihat pada tabel 1. 
Tabel 1. Kadar Bioetanol (alkohol)

\begin{tabular}{cc}
\hline Waktu fermentasi (Hari) & Kadar bioetanol (\%) \\
\hline 3 & 2,08 \\
5 & 5,21 \\
7 & 5,21 \\
9 & 3,13 \\
\hline
\end{tabular}

Waktu fermentasi juga dapat mempengaruh jumlah mikroba yang tumbuh. Banyaknya mikroba yang tumbuh dapat dihitung dengan menggunakan alat colony counter. Setelah itu banyaknya mikroba yeng terbaca oleh colony cunter dihitung lagi dengan menggunakan ketentuan untuk perhitungan mikroba.

Pada saat fermentasi hari ke 3 mikroba yang tumbuh hanya sedikit $\left(1,9 \times 10^{6}\right.$ $\mathrm{CFU} / \mathrm{mL}$ ) dikarenakan Saccharomyces cerevisiae masih dalam fase lag. Fase lag merupakan fase dimana mikroba masih beradaptasi untuk tumbuh dan menyesuaikan diri. Pada fermentasi 5 hari $\left(2,8 \times 10^{6} \mathrm{CFU} / \mathrm{mL}\right)$ dan 7 hari $\left(3,0 \times 10^{6} \mathrm{CFU} / \mathrm{mL}\right)$ jumlah mikroba sudah semakin banyak. Menurut Idral (2012) glukosa di dalam media masih banyak sehingga proses pembelahan dan aktivitas fermentasi sel Saccharomyces cerevisiae berjalan dengan baik dan bioetanol yang dihasilkan juga banyak. Pada saat fermentasi 9 hari $\left(1,2 \times 10^{6} \mathrm{CFU} / \mathrm{mL}\right)$ mikroba sudah mulai berkurang karena banyak yang mati, hal ini disebabkan karena ketersediaan nutrisi pada medium sudah mulai berkurang sehingga mikroba mengubah bioetanol menjadi asam asetat yang mengakibatkan penurunan kadar bioetanol. Glukosa dan ketersediaan nutrisi didalam media sudah hampir habis sehingga proses pembelahan dan aktivitas fermentasi sel Saccharomyces cerevisiae terhambat yang akibatnya bioetanol yang dihasilkan sedikit (Idral dkk, 2012). Banyaknya mikroba pada saat fermentasi disajikan pada gambar 2.

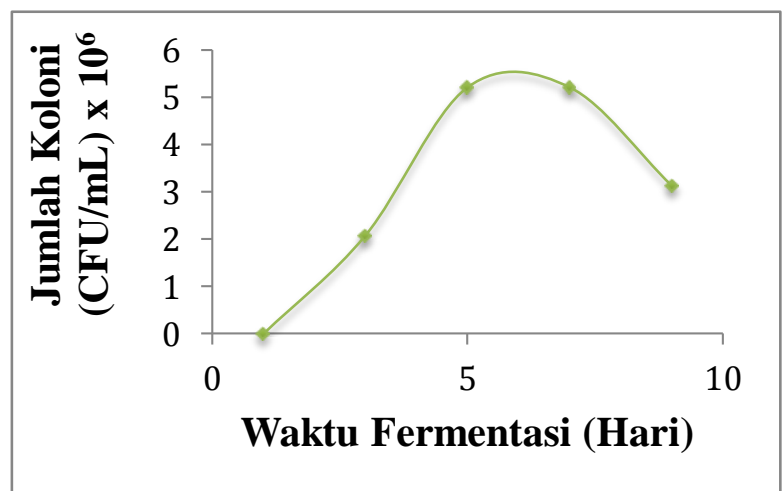

Gambar 2. Pengaruh waktu fermentasi terhadap jumlah koloni

\section{SIMPULAN}

Berdasarkan hasil penelitian dan uraian pembahasan di atas maka dapat disimpulkan bahwa, kadar glukosa terbanyak terdapat pada sampel yang dihidrolisis menggunakan $\mathrm{H}_{2} \mathrm{SO}_{4} 0,3 \mathrm{M}$ yaitu $0,161 \%$. Kadar bioetanol terbanyak dihasilkan pada fermentasi hari ke 5 dan fermentasi hari ke 7. Kadar bioetanol yang hasilkan pada fermentasi hari ke $3(2,08 \%)$, fermentasi hari ke 5 (5,21\%), fermentasi hari ke 7 $(5,21 \%)$, dan fermentasi hari ke $9(3,13 \%)$. 


\section{DAFTAR RUJUKAN}

Anieto, Ugochukwu. 2010. Biofuels. (online) http://focusnigeria.com/biofuel-nigeria.htm diakses 19 februari 2013

Arianie, Idiawati. 2011. Penentuan Lignin dan Kadar Glukosa dalm Hidrolisis Organosolv dan dan Hidrolisis Asam. Sains Terapan Kimia Vol.5 (No.2). Hal: 6

Aryaningrum. 2011. Kandungan kimia jagung dan manfaatnya bagi kesehatan. (online) http://staff.uny.ac.id/sites/default/files/tmp/artikel-ppm-jagung2.doc diakses 27 juni 2013 pukul 11:46

Balat $\mathrm{M}$, Balat $\mathrm{H}, \mathrm{Oz}$ C. 2008. Progress in bioethanol processing. Progress Energy Combustion Science 34

BPIJ. 2010. Teknik Pengembangan Budidaya Jagung Gorontalo (Binthe). (online) http:// cybex.deptan.go.id /lokalita / binthe-biluhuta-jagung - gorontalo diakses 18 februari 2013

Dewati, Retno. 2008. Limbah Kulit Pisang Kepok sebagai Bahan Baku Pembuatan Ethanol. Skripsi. UPN "Veteran" Jatim: Surabaya

Febriyanto, Endi. 2011. Spektroskopi IR dalam penentuan struktur molekul organik (online) http://endiferrysblog.blogspot.com/2011/11/spektroskopi-ir-dalampenentuan.html diakses 28 juni 2013 pukul 8:14

Fessenden dan Fessenden. (1997). Kimia Organik edisi ketiga. PT Erlangga : Jakarta.

Ginting, Inggrit. 2012. Spektroskopi IR. (online) http:// ingreat.blogspot.com /2012/06/spektoskopi-ir.html diakses 17 juli 2013 pukul 4:43

Hespell, B., 1998, Extraction and Characterization of Hemicellulose from Corn Fiber Produced by Corn Wet-Milling Processes, J. Agric. and Food Chem, 46 : 2615-2619

Idral, Salim, Mardiyah. (2012). Pembuatan bioetanol dari Ampas Sagu dengan Proses Hidrolisis Asam dan Menggunakan Saccharomyces cerevisiae. Jurnal Kimia Unand, Volume 1 (No. 1).

Ikmawati. 2011. Variasi Penambahan Ragi Pada Pembuatan Bioetanol dari Kulit Umbi Kayu (Monihot esculenta) secara fermentasi. Skripsi. Fakultas MIPA Universitas Negeri Gorontalo: Gorontalo

Isroi. 2008. Mengukur Kadar Bioetanol. (online) http:// isroi.com/2008/12/19/ mengukurkadar-bioetanol/ diakses 15 juli 2013

Kwartiningsih, Mulyati. 2005. Fermentasi sari buah nanas menjadi vinegar. EKUILIBRIUM Vol.4 (No.1) Hal: 2

Nugraheni, Purnaningsih, Novianitasari, wulandari. 2012. Materi Bakteorologi Perhitungan Jumlah Mikroba. (online) http ://desidicik.blogspot.com/2013/04/ makalah-bakteriologi-perhitungan-jumlah.html diakses 22 juni 2013 Pukul 16:28 
Raudah, Ernawati. 2012. Pemanfaatan kulit kopi arabika dari proses pulping untuk pembuatan bioetanol. Jurnal reaksi (Jurnal of science and Technology) Vol 1 (No.21)

Richana, Suwarni. (2007). Teknologi Pengolahan Jagung. (Online) http://pustaka.litbang.deptan.go.id/bppi/lengkap/bpp10249.pdf diakses 22 februari 2013 pukul 17:00

Sari, Ketut. (2009). Produksi Bioetanol dari Rumput Gajah Secara Kimia. Jurnal Teknik Kimia Vol.4 (No.1).

Soebagio. (2003). Kimia Analitik II. JICA : Malang.

Soeprijanto. (2010). Biokonversi lignoselulosa dari residu limbah pertanian menjadi biofuel melalui hidrolisis enzim dan fermentasi. Pidato Pengukuhan untuk Jabatan Guru Besar. Kementrian Pendidikan Nasioanal Institut Teknologi Sepuluh November: Surabaya

Soeprijanto. (2008). Biokonversi Selulose dari Limbah Tongkol Jagung Menjadi Glukosa Menggunakan Jamur Aspergilus Niger. Jurnal Purifikasi Vol. 9 (No . 2).

Supratman, Unang. 2008. Elusidasi Struktur Senyawa Organik. Fakultas Matematika dan IImu Pengetahuan Alam Universitas Padjadjaran. Jatinangor

Sudarmaji, Haryono, Suhardi. 1989. Analisa Bahan Makanan dan Pertanian. Penerbit Liberty Yogyakarta Bekerja Sama dengan Pusat Antar universitas Pangan dan Gizi Universitas Gadjah Mada: Yogyakarta

Thayib, Amar. 1989. Petunjuk Praktikum Mikrobiologi Pengolahan. Laboratorium Mikrobiologi Pengolahan Fakultas Teknologi Pertanian Institut Teknologi Indonesi: Serpong

Thenawijaya, Maggy. (1982). Lehninger Dasar-dasar Biokimia Jilid 1. Erlangga: Jakarta. Thenawijaya, Maggy. (1982). Lehninger Dasar-dasar Biokimia Jilid 2. Erlangga: Jakarta. Underwood. 1996. Analisa Kimia Kuantatif. Jakarta: Erlangga 